\title{
(Ga,Mn,As) compounds grown on semi-insulating GaAs with mass-analyzed low energy dual ion beam deposition
}

\author{
Junling Yang ${ }^{\mathrm{a}, *}$, NuoFu Chen ${ }^{\mathrm{a}, \mathrm{b}}$, Zhikai Liu ${ }^{\mathrm{a}}$, Shaoyan Yang ${ }^{\mathrm{a}}$, Chunlin Chai ${ }^{\mathrm{a}}$, \\ Meiyong Liao ${ }^{\mathrm{a}}$, Hongjia $\mathrm{He}^{\mathrm{a}}$ \\ ${ }^{\mathrm{a}}$ Laboratory of Semiconductor Materials Science, Institute of Semiconductor, Chinese Academy of Sciences, P.O. Box 912 , \\ Beijing 100083, People's Republic of China \\ ${ }^{\mathrm{b}}$ National Microgravity Laboratory of the Chinese Academy of Sciences, People's Republic of China
}

Received 20 August 2001; accepted 5 September 2001

Communicated by M. Schieber

\begin{abstract}
The (Ga,Mn,As) compounds were obtained by the implantation of Mn ions into semi-insulating GaAs substrate with mass-analyzed low energy dual ion beam deposition technique. Auger electron spectroscopy depth profile of a typical sample grown at the substrate temperature of $250^{\circ} \mathrm{C}$ showed that the $\mathrm{Mn}$ ions were successfully implanted into GaAs substrate with the implantation depth of $160 \mathrm{~nm}$. X-ray diffraction was employed for the structural analyses of all samples. The experimental results were greatly affected by the substrate temperature. $\mathrm{Ga}_{5.2} \mathrm{Mn}$ was obtained in the sample grown at the substrate temperature of $250^{\circ} \mathrm{C} . \mathrm{Ga}_{5.2} \mathrm{Mn}, \mathrm{Ga}_{5} \mathrm{Mn}_{8}$ and $\mathrm{Mn}_{3} \mathrm{Ga}$ were obtained in the sample grown at the substrate temperature of $400^{\circ} \mathrm{C}$. However, there is no new phase in the sample grown at the substrate temperature of $200^{\circ} \mathrm{C}$. The sample grown at $400^{\circ} \mathrm{C}$ was annealed at $840^{\circ} \mathrm{C}$. In this annealed sample $\mathrm{Mn}_{3} \mathrm{Ga}$ disappeared, $\mathrm{Ga}_{5} \mathrm{Mn}_{8}$ tended to disappear, $\mathrm{Ga}_{5.2} \mathrm{Mn}$ crystallized better and a new phase of $\mathrm{Mn}_{2} \mathrm{As}$ was generated. (C) 2002 Elsevier Science B.V. All rights reserved.
\end{abstract}

PACS: 81.05.Ea; 81.05.Zx; 81.15.Hi; 61.66.Dk; 61.82.Fk

Keywords: A1. X-ray diffraction; A3. Ion beam epitaxy; B2. Gallium arsenide

\section{Introduction}

In the field of modern information technology, semiconductor and magnetic materials are both very important. Semiconductor devices take ad-

*Corresponding author. Tel.: + 86-10-82304627; fax: + 8610-82304469.

E-mail address: yjl@red.semi.ac.cn (J. Yang). vantage of the charge of electron to process information, whereas magnetic devices such as magnetic tape take advantage of the spin of electron to record information. If the charge and spin of the electron can be combined, then it is possible to further enhance the performance of magnetic devices and semiconductor devices and prepare new types of functional devices. Furthermore, the storage and processing of information 
may be carried out at the same time. So it is very significant to integrate magnetic and semiconducting properties [1].

Up to now, there are two approaches to integrate magnetic and semiconducting properties. One is to prepare diluted magnetic semiconductor, in which a large amount of magnetic ions are incorporated into a compound semiconductor [2-4]. The other approach is to prepare magnet/ semiconductor hybrid structures. There are two kinds of magnet/semiconductor hybrid structures. One is obtained by preparing epitaxial magnetic thin film on semiconductor substrates [5-13], the other involves embedding magnetic particles in a semiconductor substrate to form a kind of granular film [14,15].

As an important semiconductor material, GaAs is extensively used in high speed electronic devices and optoelectronic devices. If we can prepare GaAs-based diluted magnetic semiconductors or magnet/GaAs hybid structure, then magnetic phenomena can be introduced into conventional nonmagnetic GaAs-based optical and electrical devices.

In this paper, (Ga,Mn,As) compounds- $\mathrm{Ga}-$ $\mathrm{Mn}$ and $\mathrm{Mn}-\mathrm{As}$ phases-were grown on semiinsulating GaAs substrates by the implantation of magnetic elemental $\mathrm{Mn}$ into GaAs substrate at certain substrate temperatures with mass-analyzed low energy dual ion beam deposition technique.

\section{Material preparation}

Samples were prepared by mass-analyzed low energy dual ion beam deposition apparatus which consists of ion beam systems and vacuum systems. One of its advantages is to purify ions by its magnetic analyzer.

Mn ions were uniformly deposited on semiinsulating GaAs (001) with Mn ion energy of $1000 \mathrm{eV}$ and a dose of $1.5 \times 10^{18} \mathrm{Mn}^{+} / \mathrm{cm}^{2}$. All GaAs substrates were etched and cleaned before sample growth. Purity of Mn used in the experiment was $99.98 \%$. Mn did not need to be etched and cleaned because of the purifying function of the growing apparatus itself. In order to remove the absorbed impurities on the surface of the GaAs substrate, the substrate was bombarded by Argon ion for $10 \mathrm{~min}$. During the growth, the GaAs substrates were heated to the scheduled temperature $\left(200^{\circ} \mathrm{C}\right.$ for sample $1,250^{\circ} \mathrm{C}$ for sample 2 and $400^{\circ} \mathrm{C}$ for sample 3 ). It took $60 \mathrm{~min}$ to grow each sample.

Sample 3 was annealed at an atmosphere of flowing $\mathrm{N}_{2}$ at $840^{\circ} \mathrm{C}$ in an automatically temperature-conditioned annealing furnace for $70 \mathrm{~min}$ and the flowing rate of $\mathrm{N}_{2}$ is $0.5 \mathrm{l} / \mathrm{min}$. During the annealing process, the sample surface clings to a polished GaAs wafer so as to prevent $\mathrm{Mn}$ from evaporating from the sample surface.

\section{Measurement and analyses}

In order to investigate the structure and distribution of $\mathrm{Mn}$ ions along the depth, X-ray diffraction (XRD) and Auger electron spectroscopy (AES) were employed for structural and compositional analyses.

\subsection{Compositional analyses}

AES was employed for analyzing the surface composition of sample 2 and its compositional variation along the cross section. The AES system used in this experiment is PHI-610/SAM. In order to analyze elemental composition at the sample surface, it was measured with AES. The AES spectra showed that there is manganese, gallium, arsenic, carbon, sulfur and oxygen at the sample surface (see Fig. 1).

Fig. 2 is the AES depth profile of sample 2, from which it can be seen that the concentration of element $\mathrm{Mn}$ reaches the maximum at a depth of $30 \mathrm{~nm}$. The reason for the existance of carbon and sulfur is that the sample surface was contaminated after the sample was taken from the growth chamber. The element oxygen was introduced by oxidation of manganese after the sample was taken from the growth chamber. At the sample surface, the concentration of oxygen is as high as $48 \%$ indicating that $\mathrm{Mn}$ is easily oxidized. Although the oxygen is very high at the surface, it decreases rapidly along the depth. During the whole analyzed depth area, the relative concentration of 


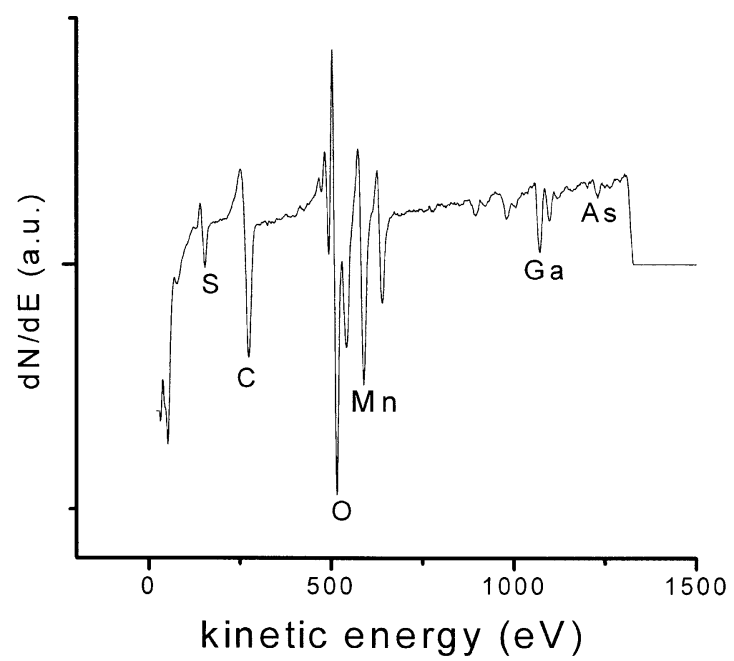

Fig. 1. Auger electron spectroscopy spectra at the surface of sample 2 .

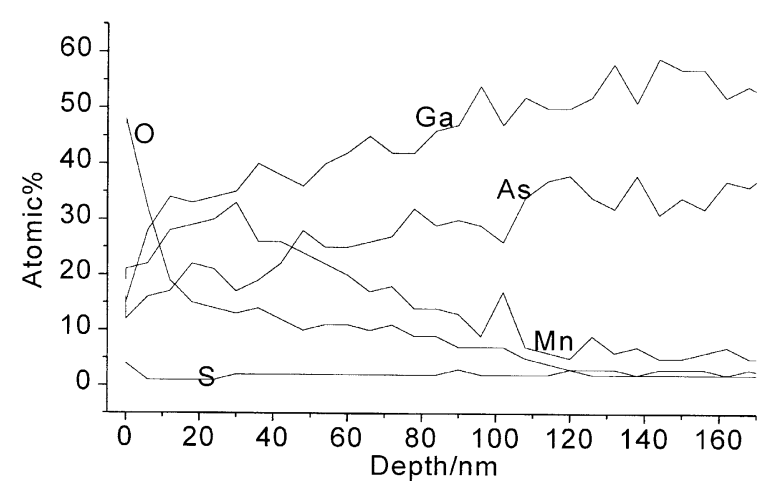

Fig. 2. Auger electron spectroscopy depth profile of sample 2.

Mn does not monotonically decrease, indicating that there is a segregation of $\mathrm{Mn}$ atoms in the sample.

\subsection{Structural analyses}

XRD patterns of the sample were measured with $2 \theta-\theta$ scan using $\mathrm{Cu} \mathrm{K}_{\alpha}$ radiation for structural analyses. Fig. 3 is the XRD spectra of sample 1, from which it can be seen that there is no new phase in sample 1. Fig. 4 is the XRD spectra of sample 2, from which it can be seen that there are two new phases, $\mathrm{Ga}_{5.2} \mathrm{Mn}$ and $\gamma-\mathrm{Mn}_{2} \mathrm{O}_{3}$. The structure system of $\mathrm{Ga}_{5.2} \mathrm{Mn}$ is orthorhombic with the lattice constants $a=5.299 \mathrm{~nm}, b=5.381 \mathrm{~nm}$

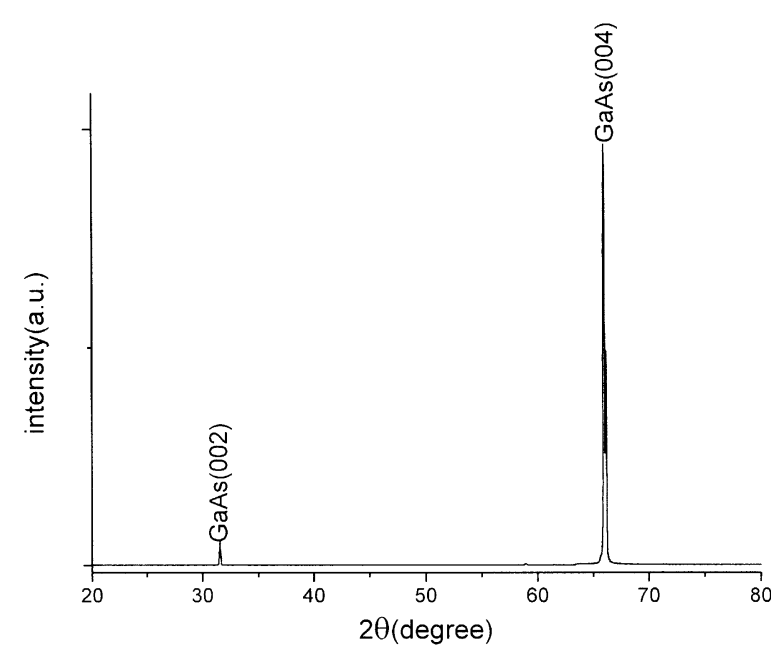

Fig. 3. X-ray diffraction spectra of sample 1.

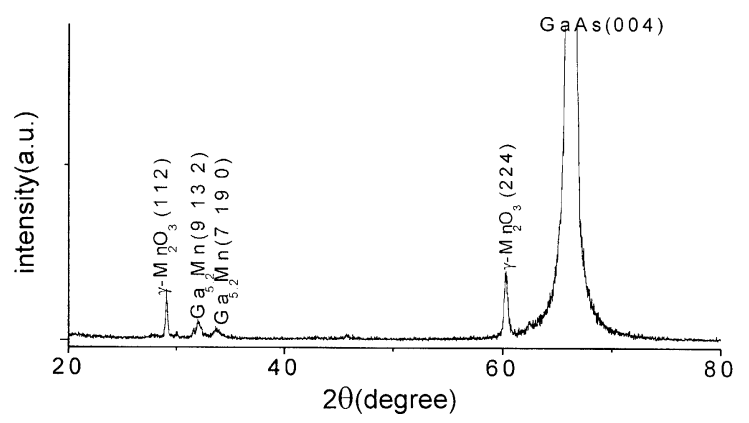

Fig. 4. X-ray diffraction spectra of sample 2.

and $c=0.994 \mathrm{~nm}$. In Fig. 4, the highest peak is from the diffraction of GaAs (004). At the left of GaAs $\left(\begin{array}{lll}0 & 4\end{array}\right)$ peak, there are four peaks which are in sequence from the diffraction of $\gamma-\mathrm{Mn}_{2} \mathrm{O}_{3}$ (112), $\mathrm{Ga}_{5.2} \mathrm{Mn}$ (9132), Ga ${ }_{5.2} \mathrm{Mn}$ (7 190) and $\gamma-\mathrm{Mn}_{2} \mathrm{O}_{3}$ (224). Fig. 5 is the XRD spectra of sample 3, from which it can be seen that there are four phases except GaAs, $\mathrm{Ga}_{5.2} \mathrm{Mn}, \mathrm{Ga}_{5} \mathrm{Mn}_{8}$, $\alpha-\mathrm{Mn}$ and $\mathrm{Mn}_{3} \mathrm{Ga}$. The crystal structure of $\alpha-\mathrm{Mn}$ is FCC with lattice constant $a=0.89121 \mathrm{~nm}$. The structure of $\mathrm{Ga}_{5} \mathrm{Mn}_{8}$ is the cubic system with the lattice constant $a=0.8992 \mathrm{~nm}$. The structure of $\mathrm{Mn}_{3} \mathrm{Ga}$ is hexagonal with the lattice constants $a=0.5404 \mathrm{~nm}$ and $c=0.4357 \mathrm{~nm}$. In Fig. 5, the highest peak is from the diffraction of GaAs $\left(\begin{array}{ll}0 & 4\end{array}\right)$. At the left of GaAs (0 04$)$ peak, there are seven diffraction peaks which are in sequence from 


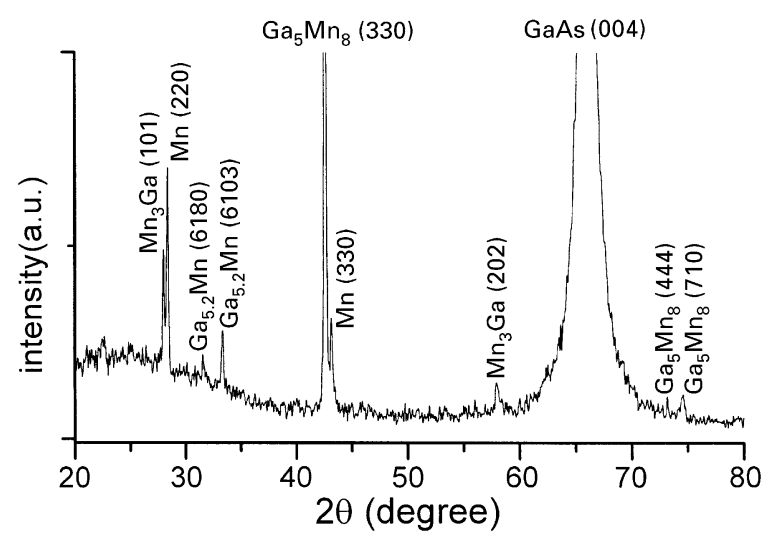

Fig. 5. X-ray diffraction spectra of sample 3 before annealing.

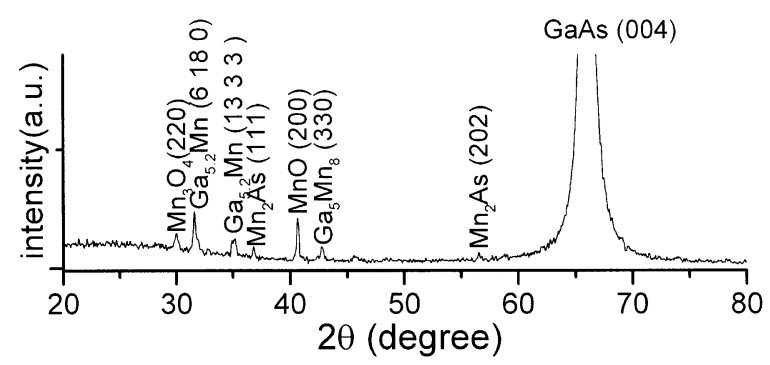

Fig. 6. X-ray diffraction spectra of sample 3 after annealing.

the diffraction of $\mathrm{Mn}_{3} \mathrm{Ga}$ (1 01 ), $\alpha$-Mn (220), $\mathrm{Ga}_{5.2} \mathrm{Mn}$ (6180), $\quad \mathrm{Ga}_{5.2} \mathrm{Mn}$ (6103), $\mathrm{Ga}_{5} \mathrm{Mn}_{8}$ (3 30 ), $\alpha$-Mn (330) and $\mathrm{Mn}_{3} \mathrm{Ga}$ (202). At the right of GaAs (004) peak, there are diffraction peaks of $\mathrm{Ga}_{5} \mathrm{Mn}_{8}$ (444) and $\mathrm{Ga}_{5} \mathrm{Mn}_{8}$ (710). The peak of $\mathrm{Ga}_{5} \mathrm{Mn}_{8}$ (3 30 ) in sample 3 is very strong and narrow indicating that the growth conditions of sample 3 are quite suited to the nucleation and growth of $\mathrm{Ga}_{5} \mathrm{Mn}_{8}$.

These XRD patterns showed that there are new $\mathrm{Ga}-\mathrm{Mn}$ compounds in both samples 2 and 3 and there is no new phase in sample 1. Furthermore, there are more compounds of $\mathrm{Ga}_{5} \mathrm{Mn}_{8}, \alpha-\mathrm{Mn}$ and $\mathrm{Mn}_{3} \mathrm{Ga}$ in sample 3 than in sample 2. It is evident that the substrate temperature is critical to the formation and disappearance of Ga-Mn and $\mathrm{Mn}$-As compounds. The reason for the appearance of $\alpha$-Mn peak in sample 3 is that the implanted $\mathrm{Mn}$ is crystallized better because of the high substrate temperature compared with samples 1 and 2 .
Fig. 6 is the XRD spectra of sample 3 after annealing, from which it can be seen that there are five phases besides $\mathrm{GaAs}, \mathrm{Ga}_{5.2} \mathrm{Mn}, \mathrm{Ga}_{5} \mathrm{Mn}_{8}$, $\mathrm{Mn}_{2} \mathrm{As}, \mathrm{Mn}_{3} \mathrm{O}_{4}$ and $\mathrm{MnO}$. The crystal system of $\mathrm{Mn}_{2} \mathrm{As}$ is tetragonal with the lattice constants $a=0.3767 \mathrm{~nm}$ and $c=0.6277 \mathrm{~nm}$. In Fig. 5, the highest peak is from the diffraction of GaAs $(004)$. At the left of GaAs (004) peak, there are eight diffraction peaks which are in sequence from the diffraction of $\mathrm{Mn}_{3} \mathrm{O}_{4}(220), \mathrm{Ga}_{5.2} \mathrm{Mn}$ (6 180), $\mathrm{Ga}_{5.2} \mathrm{Mn}$ (1333), $\mathrm{Mn}_{2} \mathrm{As}$ (1 1 1), $\mathrm{MnO}$ (200), $\mathrm{Ga}_{5} \mathrm{Mn}_{8}$ (3 30 ) and $\mathrm{Mn}_{2} \mathrm{As}$ (20 2). After annealing at $840^{\circ} \mathrm{C}, \mathrm{Mn}_{3} \mathrm{O}_{4}, \mathrm{MnO}$ and $\mathrm{Mn}_{2} \mathrm{As}$ appeared, whereas $\mathrm{Mn}_{3} \mathrm{Ga}$ and $\alpha$-Mn disappeared. $\mathrm{Mn}_{3} \mathrm{O}_{4}$ and $\mathrm{MnO}$ are the products of oxidation of $\mathrm{Mn}$ due to the intake of oxygen into the annealing atmosphere. Furthermore, manganese oxides may crystallize well at a high annealing temperature. The appearance of $\mathrm{Mn}_{2} \mathrm{As}$ shows that $\mathrm{Mn}_{2} \mathrm{As}$ can nucleate and grow at the high temperature of $840^{\circ} \mathrm{C}$. The disappearance of $\alpha-\mathrm{Mn}$ resulted partially from the combination of $\mathrm{Mn}$ with the elements $\mathrm{Ga}$ and As, and partially resulted from the oxidation of $\mathrm{Mn}$ at the high temperature of $840^{\circ} \mathrm{C}$. The disappearance of $\mathrm{Mn}_{3} \mathrm{Ga}$ suggests that $\mathrm{Mn}_{3} \mathrm{Ga}$ is not stable at $840^{\circ} \mathrm{C}$. At the same time, the intensity peak of $\mathrm{Ga}_{5} \mathrm{Mn}_{8}$ largely decreases, indicating that $\mathrm{Ga}_{5} \mathrm{Mn}_{8}$ is also unstable at $840^{\circ} \mathrm{C}$. After annealing, the diffraction peaks of $\mathrm{Ga}_{5.2} \mathrm{Mn}$ become slightly stronger and sharper, indicating that $\mathrm{Ga}_{5.2} \mathrm{Mn}$ is crystallized better during annealing. The annealing was beneficial to the growth of $\mathrm{Ga}_{5.2} \mathrm{Mn}$ and $\mathrm{Mn}_{2} \mathrm{As}$.

According to the above results, $\mathrm{Ga}_{5.2} \mathrm{Mn}$ is the only new compound in the sample grown at a low temperature of $250^{\circ} \mathrm{C}$. At the same time, $\mathrm{Ga}_{5.2} \mathrm{Mn}$ existed in the sample grown at $400^{\circ} \mathrm{C}$ and crystallized better during annealing at $840^{\circ} \mathrm{C}$. These facts indicate that it is easy for $\mathrm{Ga}_{5.2} \mathrm{Mn}$ to nucleate and grow and $\mathrm{Ga}_{5.2} \mathrm{Mn}$ is stable over a wide range of temperatures.

\section{Summary}

(Ga,Mn,As) compounds were obtained with mass-analyzed low energy dual ion beam 
deposition with $\mathrm{Mn}$ ion energy of $1000 \mathrm{eV}$ and a dose of $1.5 \times 10^{18} \mathrm{Mn}^{+} / \mathrm{cm}^{2}$. The substrate temperature is very important in preparing samples. There is a difference between the samples grown at different substrate temperatures. There was no new phase in the sample grown at $200^{\circ} \mathrm{C}$. There is only one $\mathrm{Ga}-\mathrm{Mn}$ phase, $\mathrm{Ga}_{5.2} \mathrm{Mn}$, in the sample grown at $250^{\circ} \mathrm{C}$ and there are three $\mathrm{Ga}-\mathrm{Mn}$ phases, $\mathrm{Ga}_{5.2} \mathrm{Mn}, \mathrm{Ga}_{5} \mathrm{Mn}_{8}$ and $\mathrm{Mn}_{3} \mathrm{Ga}$, in the sample grown at $400^{\circ} \mathrm{C}$. After the sample grown at $400^{\circ} \mathrm{C}$ was annealed at $840^{\circ} \mathrm{C}$, the $\mathrm{Mn}_{3} \mathrm{Ga}$ disappeared, $\mathrm{Ga}_{5} \mathrm{Mn}_{8}$ tends to disappear, $\mathrm{Mn}_{2} \mathrm{As}$ appeared and $\mathrm{Ga}_{5.2} \mathrm{Mn}$ crystallized better. The annealing was beneficial to the growth of $\mathrm{Ga}_{5.2} \mathrm{Mn}$ and $\mathrm{Mn}_{2} \mathrm{As}$. It is also evident that $\mathrm{Ga}_{5.2} \mathrm{Mn}$ is stable over a wide range of temperatures.

\section{Acknowledgements}

This work was partially supported by special funds for Major State Basic Research Project G20000683, and by the Ministry of Chinese National Science and Technology under contract PAN95-YU-34.

\section{References}

[1] H. Ohno, Science 281 (1998) 951.

[2] H. Ohno, Appl. Phys. Lett. 69 (1996) 363.

[3] W. Van Roy, H. Akinaga, S. Miyanishi, K. Tanaka, L.H. Kuo, J. Magn. Magn. Mater. 165 (1997) 149.

[4] T. Hayashi, M. Tanaka, K. Seto, T. Nishinaga, K. Ando, Appl. Phys. Lett. 71 (1997) 1825.

[5] J.R. Waldrop, R.W. Grant, Appl. Phys. Lett. 34 (1979) 630.

[6] G.A. Prinz, J.J. Krebs, Appl. Phys. Lett. 39 (1981) 397.

[7] G.A. Prinz, Science 250 (1990) 1092.

[8] G.A. Prinz, Phys. Today (Special Issue on Magnetoelectronics) 48 (1995) 58.

[9] M. Tanaka, J. Crystal Growth 201/202 (1999) 660.

[10] P.M. Thibaro, E. Kneedler, B.T. Jonker, B.R. Bennett, B.V. Shanabrook, L.J. Whitman, Phys. Rev. B 53 (1996) R10481.

[11] T. Sands, J.P. Harbison, M.L. Leadbeater, S.J. Allen, G.W. Hull, R. Ramesh, V.G. Keramidas, Appl. Phys. Lett. 57 (1990) 2609.

[12] M. Tanaka, J.P. Harbison, M.C. Park, Y.S. Park, T. Shin, M. Rothberg, Appl. Phys. Lett. 65 (1994) 1964.

[13] S. Miyanishi, H. Akinaga, W. VanRoy, K. Tanaka, Appl. Phys. Lett. 70 (1997) 2046.

[14] E.E. Fullerton, J.E. Mattson, S.R. Lee, C.H. Sowers, Y.Y. Huang, G. Felcher, S.D. Bader, F.T. Parker, J. Magn. Magn. Mater. 117 (1992) L301.

[15] H. Akinaga, J. De Boeck, G. Borghs, Appl. Phys. Lett. 72 (25) (1998) 3368. 